\title{
CONGENITAL, STATIC FAMILIAL OPHTHALMOPLEGIA
}

BY

\section{F. LEES}

\section{From the Department of Neurology, Manchester Royal Infirmary, Manchester}

Ophthalmoplegia with ptosis occurring as a hereditary congenital, static condition is rare (Walsh, 1957). Only a small number of affected families has been described. Many other descriptions refer to progressive disease which appears to be a different heterogeneous group of ophthalmoplegias (Beckett and Netsky, 1953; Helfand, 1939; Hutchinson, 1879; Langdon and Cadwalader, 1928; Lewis, 1956; Walsh, 1957; Wilbrand and Saenger, 1900). In the family recorded here the defect was present in at least three generations. Clinical observations on four afflicted members of the family are available.

\section{Clinical Details}

Case 1.-(A.B.). This boy (Fig. 1), an apprentice plumber aged 16 years, complained that he could not raise the upper eyelids and that sometimes he had to "blink" in order to bring approaching objects "into focus". The ptosis was congenital and because of it he had to tilt his head backwards to obtain a horizontal gaze. He had observed that the eyeballs would not move upwards under any circumstances. Lateral gaze required rotation of the head. He frequently collided with his companions as they walked beside him. He did not attend hospital because of any new or distressing symptoms but because a friend was attending and he thought he would like to know what was wrong with his eyes and whether any treatment could be given. He had worn glasses since an early age. There had been no diplopia. He was quite intelligent and walked with a backward tilt of the head. There was severe bilateral ptosis, the left palpebral fissure being a little narrower than the right. It was easy to lift the lids mechanically and this showed both globes to be permanently rotated downwards. Fig. 2 shows attempted eye movements. A suggestion of bilateral facial weakness in the expression was not confirmed by testing facial movements, which were powerful. Upward eye movement was lost bilaterally. The right eye showed almost complete external ophthalmoplegia, only a trace of downward movement being observed. The left eye showed a little medial and lateral movement. These excursions were accompanied by a slight rotation of the globe and variable rotatory and horizontal nystagmoid oscillations. The left pupil was very slightly larger than the right but both showed normal reactions to light, directly and consensually. Convergence movements were negligible and no accommodation pupillary reaction was seen during these attempts. Fixation of vision on a static object failed to improve eye movement when the head was moved in any direction. Vision without correction was, right eye 6/24 and left eye (the more mobile eyej $6 / 9$. With glasses, right eye $6 / 18$, left eye 6/6. The visual fields were full. The right field showed a blind spot of normal size and position but none could be found in the left eye field. The left eye was in fact oscillating continuously on attempted fixation. There were no other abnormal signs. An intravenous dose of $10 \mathrm{mg}$. of edrophonium ("tensilon") did not facilitate eye or eyelid movement.

Case 2.-L.B., aged 43 is the father of A.B. (Fig. 3).

He brought his wife and the affected members of the family. They confirmed that the ocular defects had been

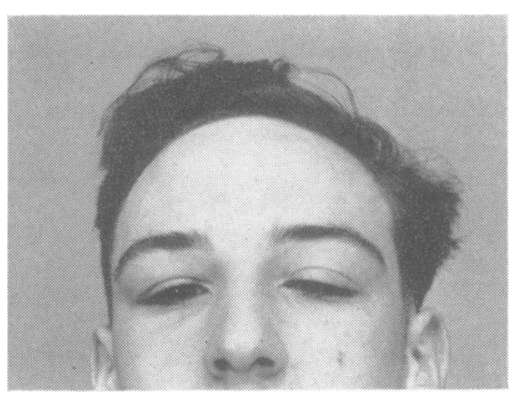

FIG. 1.-Case 1 (A.B.).

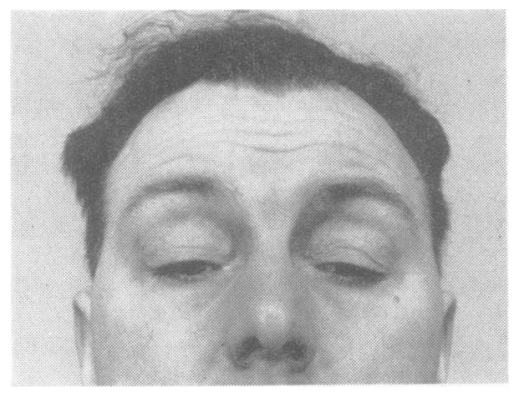

Fig. 3.-Case 2 (L.B.). 


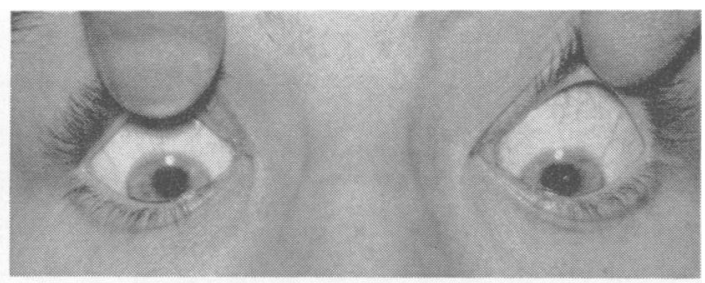

FIG. $2 a$

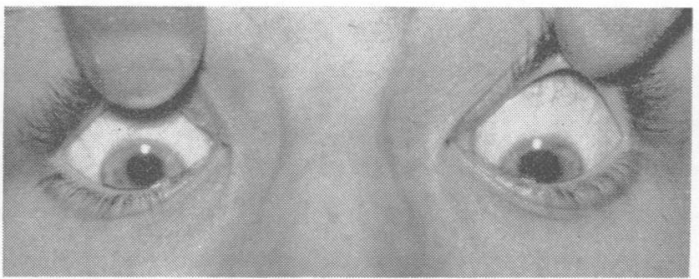

FIG. $2 b$

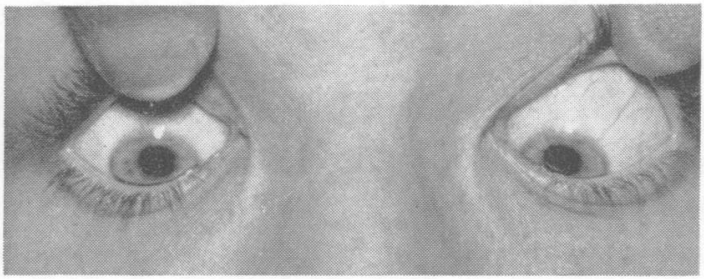

FIG. 2c

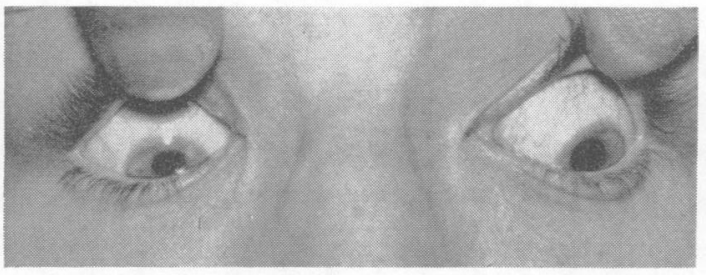

FIG. $2 d$

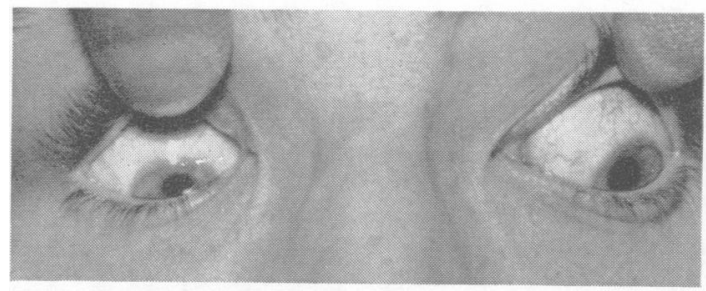

FIG. $2 e$

FIG. 2.-Case 1: attempted eye movements.
(a) Looking upward
R. nil.
L. nil.
(b) Forward gaze
(c) Looking right
(d) Looking left
R. nil.
R. $5^{\circ}$.
L. $35^{\circ}$.
(e) Looking downwards R. $10^{\circ}$
L. $40^{\circ}$.

The forward gaze position shows the permanent downward rotation of the eyeballs revealed by lifting up the lids.

The degrees of movement are measured from the anteroposterior axis and are approximate.

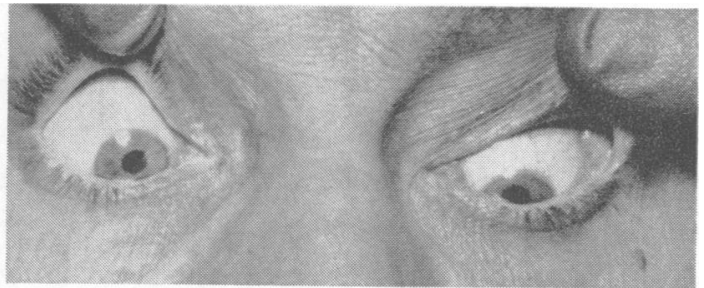

FIG. $4 a$

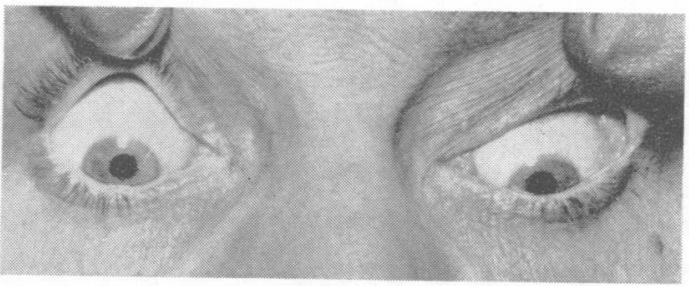

FIG. $4 b$

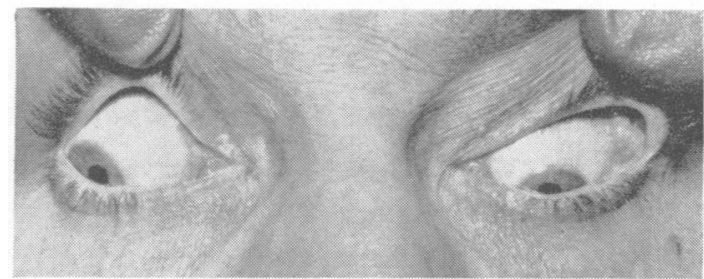

FIG. $4 c$

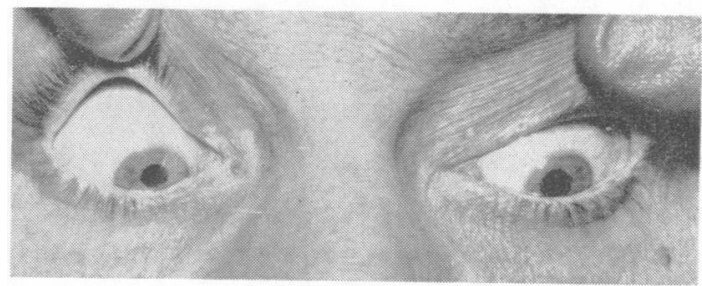

FIG. $4 d$

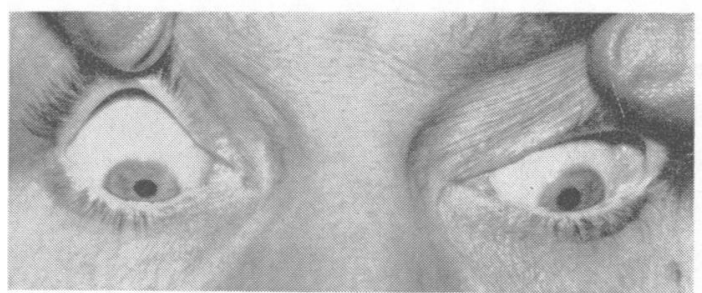

Fig. $4 e$

Fig. 4.-Case 2: attempted eye movements.
(a) Looking upwards R. nil.
L. nil.
(b) Forward gaze Shows permanent downward
(c) Looking right
R. $40^{\circ}$ L. nil.
(e) Looking downwards R. nil.

The degrees of movement from the mid-line are approximate. 
present at birth and that no progression whatever had been observed. His own story was that of bilateral congenital ptosis, walking with the head held back, and that on testing himself he had found the left eye to be quite fixed and the right to have only minimal movement. He was "easily put off balance if bumped into". He had severe bilateral ptosis with permanent wrinkling of the forehead. Attempted eye movements are shown in Fig. 4. No vertical eye movement was present. The left eye was practically immobile. There was slight horizontal movement in the right eye. The left pupil was slightly larger than the right and both showed normal reflexes except on convergence. The more mobile right eye showed nystagmoid oscillations on attempted movements. He had a mournful appearance but no loss of power in the facial muscles.

Case 3.-E.B., the second son of L.B., was 7 years of age and was born with bilateral ptosis and a downward tilt of both eyes, the left more than right (Fig. 5). Attempted

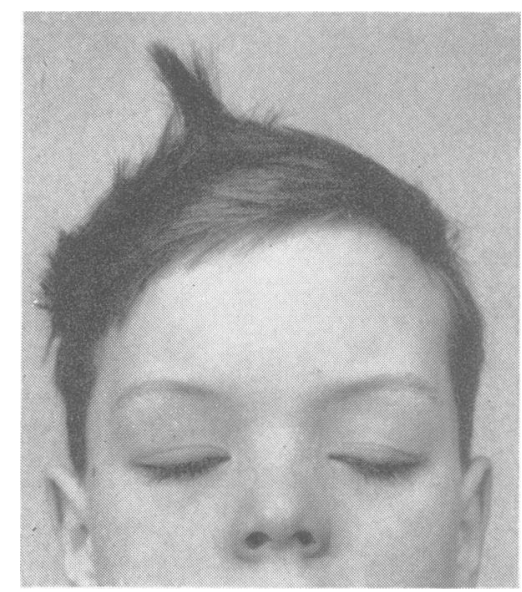

FIG. 5.-Case 3 (E.B.).

eye movements are shown in Fig. 6. There was a little horizontal mobility of the right eye only. There was an intermittent convergent strabismus but the left eye was fixed. No vertical excursion was shown by either eye. Nystagmoid jerks were exhibited by the right eye on movement. The right pupil was slightly larger than the left. Pupillar reactions were the same as in the other cases.

Case 4.-P.B., the daughter of L.B., was 8 months old (Fig. 7). She was born with bilateral unequal ptosis and unequal downward rotation of the eyeballs, both more marked on the right. A frequent but variable convergent strabismus was present. In this case the left eye was almost fixed and the only movement on the right was a short horizontal excursion with nystagmoid oscillations. The pupils were equal in size.

None of the patients had any other detectable congenital or neurological lesion. The muscular power in the

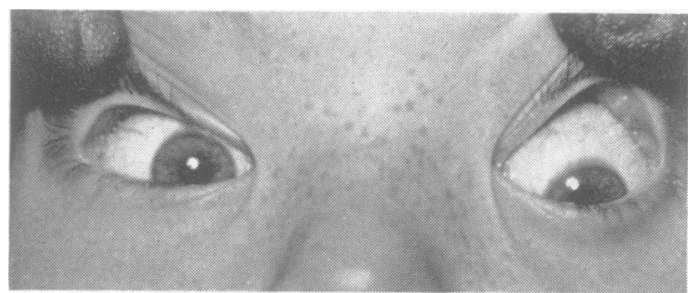

FIG. $6 a$

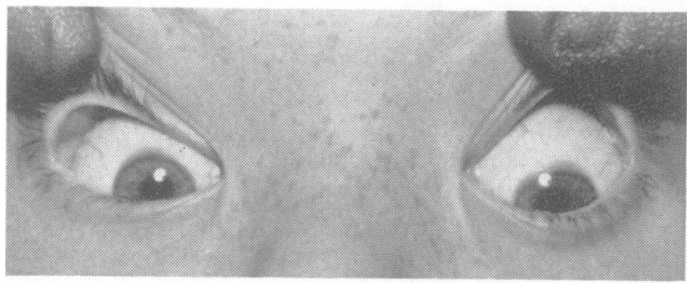

FIG. $6 b$

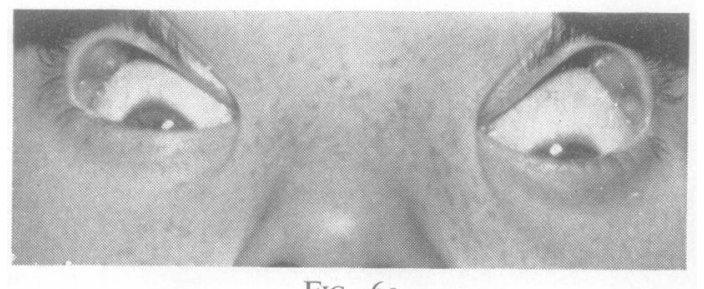

FIG. $6 c$

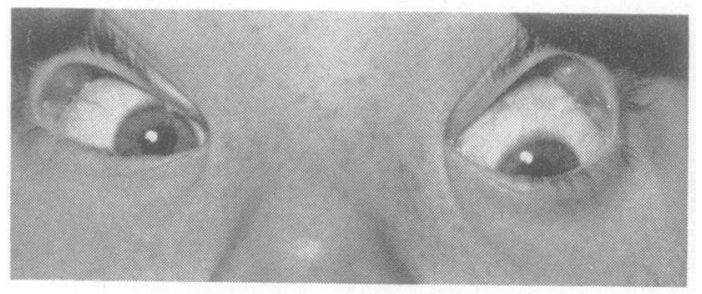

FIG. $6 d$

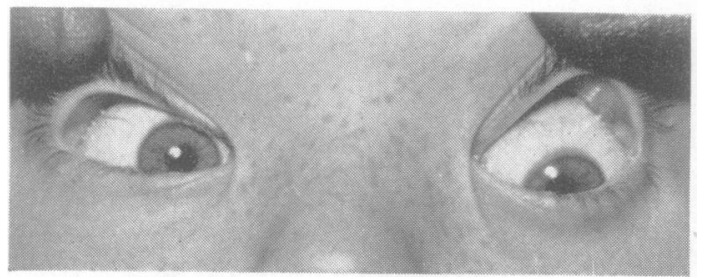

FIG. 6e

FiG. 6.-Case 3: attempted eye movements.

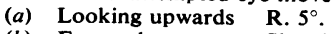
L. nil.
(b) Forward gaze
Showing downward rotation.
(c) Looking right
(d) Looking left
more marked in the left eye.
R. $10^{\circ}$
L. nil.
L. nil.
The degrees of movement are approximate. 


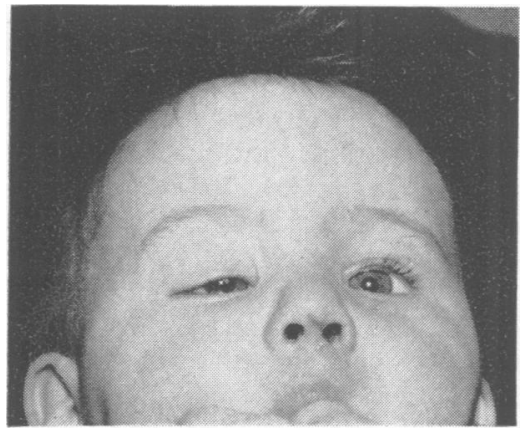

FIG. 7.-Case 4 (P.B.).

limbs, shoulder and pelvic girdles was normal. The tendon reflexes in the arms and legs were all present and equal. The plantar responses were flexor. There was no sign of muscular wasting or of pseudohypertrophy. Movements of the limbs and gait were normal. Sensory testing in all modalities revealed no deviation from normal.

\section{Family History}

L.B. believes that his grandparents were not affected. His father, who died aged 78, after a healthy life, was affected with ptosis and walked with head held back. There were two sisters and two brothers in that generation, one of each of which had ptosis and ophthalmoplegia. One of these women had an "unsuccessful" operation on the eyes. What is known of the rest of the family is shown in

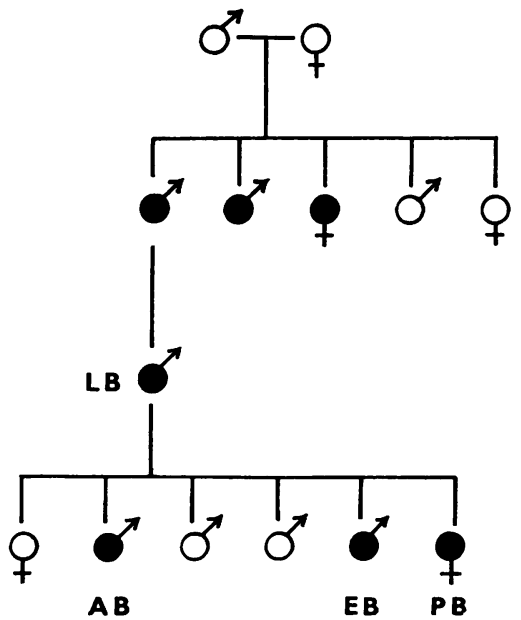

AFFECTED

HEALTHY

Fig. 8.-The affected family.
Fig. 8. There are three unaffected children in the family studied.

\section{Discussion}

The most interesting point of discussion is the possible site of the lesion causing this syndrome. Bilateral ptosis, defective vertical eye movements, downward rotation, a fixed eye and a slightly mobile eye, nystagmoid jerks, and unequal pupils were the chief features. Supranuclear optic fixation reflexes did not cause free eye movements (Wilson, 1954). The absence of a blind spot in A.B., the rest not being tested, probably indicated that a fixation point for gaze had not developed and was accompanied by the continuous oscillatory or scanning movements of the "mobile" eye.

There was no evidence of progression, facial nerve affection, or any lesion of the sympathetic nervous system.

Ptosis and loss of vertical, especially upward, eye movement are the main features of Parinaud's syndrome (Walsh, 1957) which is said to be the result of a supranuclear lesion in or near the posterior longitudinal bundle at the level of the posterior commissure or superior colliculus. Lesions at or near the pineal gland may produce this syndrome which may include other features, namely, pupillary abnormalities, because the lesion is in the region of the pupillomotor pathway, and defects of convergency and accommodation and diplopia if nuclear lesions are also present. The ptosis is ascribed to a lesion in the anterior part of the mesencephalic grey matter. The ophthalmoplegia in this family might then be due to a posterior longitudinal bundle lesion combined with nuclear dysfunction. If the connecting fibres from the bundle to the sixth nerve nuclei were also involved this might account for a defect in lateral eye movements. Double vision may be absent with optic axes not parallel because one image is disregarded after a time. Loss of accurate fixation disturbs vision and causes the eye to oscillate, especially if the object is not at the centre of vision. A certain loss of stability when walking was noticed by A.B. and L.B. This may be connected with the defect in horizontal eye movements or loss of the optic-vestibulo-cerebello-spinal reflexes of head-eye coordination effected through the posterior longitudinal bundle. Although the progressive type of familial ophthalmoplegia has been ascribed to a myopathy in some cases, this cause would seem to be very unlikely in the static congenital cases. The patients in this family show strikingly similar clinical pictures or are more or less "mirror images" of each other.

Cases of congenital ophthalmoplegia were separated by Wilbrand and Saenger from the less 
uncommon variety of "chronic progressive nuclear ophthalmoplegia" and they noted that congenital cases were not progressive.

Many authors have written about progressive cases. Langden and Cadwalader claimed that a nuclear dysplasia was present in one case. One of the first descriptions of this type of ophthalmoplegia was by Hutchinson in 1879. McMullen and Hine (1921) were also referring to progressive disease when they ascribed it to defective nuclear development.

Cases more like the present family were recorded by Bradburne (1912) in five generations, Lewis (1956) with three cases in one family, and Holmes (1955) who presented details of a family of 19 members, nine of whom had hereditary congenital ophthalmoplegia. None had other congenital physical or mental defects. Inheritance was congenital, not progressive, not sex linked and dominant as in our family. In the description by Holmes there was observed to be rotatory nystagmus, complete absence of vertical movement, and minimal lateral excursions. There was slight myopia not improved by glasses. Neurological examination was negative. Biopsy of an external rectus muscle showed complete replacement of muscle by relatively cellular fibrous tissue. Holmes felt that the disease might represent the combined influences of nuclear dysplasia and imperfect development of the external ocular muscles.

Gourfein's family (1896) with this disease had six affected members.

Lawford (1888) described a family in which the father, aged 45, and three children were affected. Three children were normal. The cases are very similar to ours. I think one of the most important observations of all was made by Heuck (1879) who found four cases in a family. One of them died of scarlet fever. Necropsy showed grossly abnormal external ocular muscles which were nearly all inserted into abnormal positions, particularly too far back in the sclerotic or capsule, so that adequate movements could not occur. Nearly all the muscles were too short and the superior recti and levator palpebrae superioris muscles were very thin and membranous. The nerves were normal. This case and the biopsy studies by Holmes give vital information about this defect.

It is remarkable that usually no other anomalies of development are present, though of course, infants with serious congenital defects in the nervous system may also show ophthalmoplegia. Bradburne's familial ophthalmoplegia had run through five generations of 37 individuals, affecting 16 and the seven surviving were described. He had great difficulty in persuading them to show "the family failing". The cases are very similar indeed to our family. They were congenital, not sex linked, and of continual descent, unaccompanied by any other defects. The years between 1710 and 1912 were covered by these generations. There was an equal ability to transmit in both sexes.

A rather different family was reported by Salleras and Ortiz de Zárate (1950). It suffered from a sexlinked congenital ophthalmoplegia. Six males out of seven had the condition with other coincidental signs of myopia and absent tendon reflexes. The females in the family were ophthalmologically normal but those transmitting it had no knee and ankle jerks.

The descriptions and photographs show patients like ours, with "complete bilateral ptosis", almost complete bilateral external ophthalmoplegia, squint in four of them, and slight lateral movements of less than $20^{\circ}$ in some of the eyes. The pupils were eccentric dyscoric and amisocoric and the accommodation reflex was difficult to obtain because of high myopia and lack of convergence. The combined lesions and hereditary feature indicated a dysplasia of chromosomal origin but as no pathological material was available the exact site of the lesion was not determined.

In conclusion, there are theoretical reasons for believing that the lesion in the congenital, static ophthalmoplegia is in the posterior longitudinal bundle and its nuclear connexions or possibly to some extent in the nuclei themselves but not affecting most of the pupillary function. The presence of dysplasia in this area before or during the development of the external ocular muscles might cause maldevelopment of the muscles as illustrated by the findings of Holmes and Heuck. There is no pathological proof, however, that the lesion is not a dysplasia of muscle with normal nervous connexion. References to the pathological lesions in the nerve nuclei refer to progressive ophthalmoplegia and not to the syndrome described here. Pathological studies are required if necropsy material becomes available in such families.

\section{Conclusion}

A family with congenital, static hereditary ophthalmoplegia is described. Reasons for considering that the lesion is in the posterior longitudinal bundle and its connexions with the oculomotor nuclei are advanced. The literature of some similar families is reviewed. Pathological material is lacking in most cases of this type of ophthalmoplegia. In two reports the lesion found was in the eye muscles. It is possible that the congenital defect is in muscular development and not in the nervous connexions. 
I wish to thank Dr. F. R. Ferguson for allowing me to publish the details of these patients who were under his care and also for his help in the preparation of the paper.

I also wish to thank Dr. R. Ollerenshaw and his staff for the photographs and illustration.

\section{REFERENCES}

Beckett, R. S., and Netsky, M. G. (1953). A.M.A. Arch. Neurol. Psychiat., 69, 64.

Bradburne, A. A. (1912). Trans. ophthal. Soc. U.K., 32, 142.

Gourfein, D. (1896). Rev. méd. Suisse rom., 16, 673.
Helfand, M. (1939). Arch. Ophthal. (Chicago), 21, 823.

Heuck, G. (1879). Klin. Mbl. Augenheilk., 17, 253.

Holmes, W. J. (1955). Trans. Amer. ophthal. Soc., 63, 245.

Hutchinson, J. (1879). Med. Chir. Trans. Lond., 62, 307.

Langdon, H. M., and Cadwalader, W. B. (1928). Trans. Amer. opthal. Soc., 26, 247.

Lawford, J. B. (1888), Trans. ophthal. Soc. U.K., 8, 262

Lewis, P. M. (1956). Memphis med. J., 31, 124

Lewis, P. M. (1956). Memphis med. J., 31, 124.

Salleras, A., and Ortiz de Zárate, J. C. (1950). Ibid., 34, 662.

Walsh, F. B. (1957). Clinical Neuro-ophthalmology, 2nd ed., p. 201 and 254. Williams and Wilkins, Baltimore.

Wilbrand, H., and Saenger, A. (1900). Die Neurologie des Auges, Vol. 1, pp. 117-134. Bergmann, Wiesbaden.

Wilson, S. A. Kinnier (1954). Neurology, 2nd ed., Vol. 2, p. 1156. ed. A. Ninian Bruce. Butterworth, London.

\section{THE NOVEMBER (1959) ISSUE}

The November (1959) issue contains the following papers:-

Some Observations on the Pathogenesis and Natural History of Intracranial Aneurysms. T. Crawford.

Some Sensory Syndromes in Children: Indifference to Pain and Sensory Neuropathy. T. E. Ogden, Francoise Robert, and E. Arnold Carmichael.

The Non-specificity of the Intrathecal Reaction to Tuberculin in Multiple Sclerosis. John Marshall and Francis O'Grady.

The Seasonal Incidence of Onset and Exacerbations in Multiple Sclerosis. Kurt Schapira.

The Significance in Human Stereotactic Brain Surgery of Individual Variation in the Diencephalon and Globus Pallidus. J. B. Brierley and Elisabeth Beck.

Sensory, Motor, and Reflex Changes in Two Cases of Intractable Pain after Stereotactic Mesencephalic Tractotomy: Ansgar Torvik.

Quantitative Electromyographic Changes Associated with Muscular Weakness. J. A. R. Lenman.

The Diaphragm in Dystrophia Myotonica. J. E. Caughey and N. Pachomov.

Myopathy in Cushing's Syndrome. Ragnar Müller and Eric Kugelberg.

Some Muscular Manifestations of Hypothyroidism. John Wilson and John N. Walton.

Histochemical Distribution of Phosphorylase in the Brain of the Guinea-pig. Reinhard L. Friede.

Congenital Intraorbital Arteriovenous Aneurysm. Ramón Jacas, Adolfo Ley, and Domingo Campillo.

Neurological Changes with Intracarotid Amytal and Megimide in Man. Robert Werman, Nicholas Christoff, and Paul J. Anderson.

The Prognosis for Affective Illness with Overt Anxiety. Lindsay Walker.

Proceedings of the Society of British Neurological Surgeons: 59th Meeting.

Book Reviews.

Index to Volume 22

A number of copies are still available and may be obtained from the Publishing Manager, British Medical Association, Tavistock Square, W.C.1, price 17s. $6 d$. 